\title{
Can we kill 2 birds with 1 stone?
}

\author{
Hiroshi Date, MD
}

\author{
From the Department of Thoracic Surgery Graduate School of Medicine, Kyoto University, Kyoto, Japan. \\ Disclosures: Author has nothing to disclose with regard to commercial support. \\ Received for publication Nov 13, 2016; accepted for publication Nov 15, 2016; available ahead of print Dec 10, \\ 2016. \\ Address for reprints: Hiroshi Date, MD, Department of Thoracic Surgery, Graduate School of Medicine, \\ Kyoto University, 54 Kawahara-cho, Shogoin, Sakyo-ku, Kyoto 606-8507, Japan (E-mail: hdate@kuhp. \\ kyoto-u.ac.jp). \\ J Thorac Cardiovasc Surg 2017; 153:725 \\ $0022-5223 / \$ 36.00$ \\ Copyright (c) 2016 by The American Association for Thoracic Surgery \\ http://dx.doi.org/10.1016/j.jtcvs.2016.11.036
}

Severe primary graft dysfunction (PGD) occurs in up to $15 \%$ to $25 \%$ of recipients and remains a major cause of early death after lung transplantation. ${ }^{1}$ Notably, this problem persists despite significant advancements in lung preservation and perioperative management. PGD is mainly caused by ischemia-reperfusion injury (IRI). IRI may also contribute to rejection resulting in chronic lung allograft dysfunction (CLAD), which is the major cause of late death. ${ }^{2}$ About half of lung transplant recipients develop CLAD within 5 years, resulting in disappointing longterm survival rates. It is obvious that PGD, a major cause of early death, and CLAD, major cause of late death, are the 2 major unsolved complications after lung transplantation to date.

Jungraithmayr and colleagues ${ }^{3}$ demonstrate antiinflammatory effects on IRI by the CD26/DPP4-inhibitor vildagliptin using a synergetic mouse lung transplant model. CD26/DPP4 is a transmembrane molecule with enzymatic functions that cleaves biologically active peptides. It is expressed on activated $\mathrm{T}$ and $\mathrm{B}$ cells as well as lung endothelial cells. Using the same mouse lung transplant model, this group previously showed that vildagliptin attenuated IRI for 48 hours and that this was associated with increased levels of stromal cell-derived factor-1 or vasoactive intestinal peptide. ${ }^{3}$ The current study was conducted to show longer time improvement of lung transplants from IRI for up to 2 weeks by vildagliptin. Lungs preserved with vildagliptin for 18 hours showed better compliance and less injury, evidenced by a number of molecular parameters such as tumor necrosis factor- $\alpha$, T cells, B cells, and intercellular adhesion molecules. They concluded that this study shows sustained long-term improvement of IRI after lung transplantation with vildagliptin use. It is not clear to me why vildagliptin showed long-term effects (up to 2 weeks) because it was administered only in the preserved lung. Because the early phase after reperfusion is known to be the crucial time of IRI, the long-term effect may be simply the reflection of early effect.

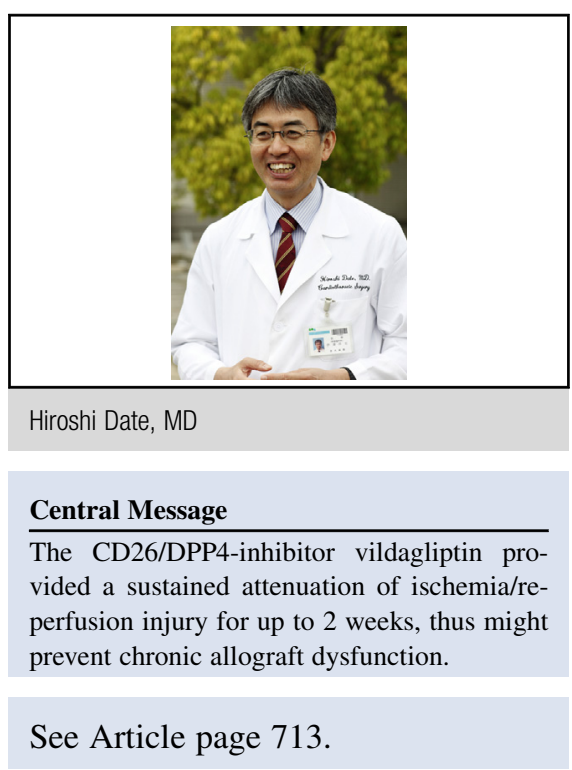

A number of substances have been reported to be effective for IRI after lung transplantation using various animal models. Among these substances, vildagliptin is unique in that it provides long-term effects on IRI, as shown in the current study, and it may also promote the lung allograft acceptance that was reported in the previous study. ${ }^{4}$ Using a mouse allo-lung transplant model, the same group reported that vildagliptin ameliorates histologic cellular acute rejection resulting in a reduction of infiltrating $\mathrm{T}$ cells. Acute rejection and IRI are known contributors to subsequent CLAD development. Therefore, vildagliptin may become a key drug to prevent PGD and CLAD, which are major complications after lung transplantation. We may be able to kill 2 birds with 1 stone.

\section{References}

1. Yusen RD, Edwards LB, Kucheryavaya AY, Benden C, Dipchand AI, Goldfarb SB, et al. The registry of the International Society for Heart Lung Transplantation: Thirty-second official adult lung and heart-lung transplantation report -2015; focus theme: early graft failure. J Heart Lung Transplant. 2015; 34:1264-77.

2. Sato M. Chronic lung allograft dysfunction after lung transplantation: the moving target. Gen Thorac Cardiovasc Surg. 2013;61:67-78.

3. Jungraithmayr W, De Meester I, Matheeussen V, Baerts L, Arni S, Weder W CD26/DPP-4 inhibition recruits regenerative stem cells via stromal cell-derived factor-1 and beneficially influences ischaemia-reperfusion injury in mouse lung transplantation. Eur J Cardiothorac Surg. 2012;41:1166-73.

4. Yamada Y, Jang JH, De Meester I, Baerts L, Vliegen G, Inchi I, et al CD26 costimulatory blockade improves lung allograft rejection and is associated with enhanced interleukin-10 expression. J Heart Lung Transplant. 2016;35:508-17. 